\title{
Relative Time Course of Degeneration of Different Cochlear Structures in the CD/1 Mouse Model of Accelerated Aging
}

\author{
Shanthini Mahendrasingam, Jamie A. MacDonald, and David N. Furness \\ Institute for Science and Technology in Medicine and the School of Life Sciences, Keele University, Keele, Staffordshire ST5 5BG, \\ $U K$
}

Received: 19 September 2010; Accepted: 22 February 2011; Online publication: 12 March 2011

\begin{abstract}
Presbycusis (age-related hearing loss) can result from various cochlear pathologies. We have studied the time course of degeneration in a mouse that shows accelerated presbycusis, the $\mathrm{CD} / 1$ mouse, as a possible model to investigate stem-cell strategies to prevent or ameliorate presbycusic changes. $\mathrm{CD} / 1$ mice from 0 to 72 weeks old were examined by light and electron microscopy. Early pathological changes were detected in basal turn spiral ligament fibrocytes and spiral ganglion, but the latter was variable as both satellite cells and neurons were normal in some cochleae. Light microscopic counts in the spiral ligament of 20week-old mice revealed that of the five main types (types $\mathrm{I}-\mathrm{V}$ ), only type $\mathrm{V}$ fibrocytes showed no reduction in numbers compared with 3-week-old animals, and type IV showed the greatest losses. However, all types of fibrocyte showed subtle damage when examined using electron microscopy, in the form of swollen mitochondria, as early as 2 weeks. The extent of mitochondrial damage showed a degree of correspondence with the light microscopic pattern of fibrocyte loss in that types III and IV fibrocytes had the most abnormal mitochondria and type $\mathrm{V}$ the least, especially at early stages. By 10-15 weeks, ultrastructural features of fibrocyte damage were similar to longer term changes reported in gerbils. Stria vascularis, spiral ganglion and hair cells showed few consistent early signs of damage but became increasingly affected, lagging behind the fibrocyte damage. Our data suggest that fibrocyte pathology may precede other presbycusic
\end{abstract}

Correspondence to: David N. Furness - Institute for Science and Technology in Medicine and the School of Life Sciences - Keele University · Keele, Staffordshire ST5 5BG, UK. Telephone: +44-1782733496; fax: +44-1782-733516; email: coa14@keele.ac.uk changes; breakdown of homeostatic mechanisms to which they contribute may cause the subsequent degeneration of the hair cells. Overall, there were many similarities to presbycusic changes in other rodents and humans. Therefore, the features of accelerated aging in this mouse make it a suitable model for rapidly assessing possible strategies to prevent or ameliorate presbycusic changes.

Keywords: cochlea, spiral ligament, fibrocytes, agerelated hearing loss, presbycusis

\section{INTRODUCTION}

There are four main forms of age-related hearing loss (presbycusis) in humans, three of which are sensory, neural (affecting primarily the hair cells and spiral ganglion (SG)) and strial degeneration (Schuknecht and Gacek 1993), where the lateral wall (stria vascularis (SV) and spiral ligament (SL)) deteriorates. In lateral wall degeneration, the SL degenerates before the SV (Kusunoki et al. 2004) or hair cells.

The development of stem-cell technology offers a means to repair the damaged or presbycusic cochlea (Hildebrand et al. 2008) or prevent presbycusis with timely intervention. The outbred $\mathrm{CD} / 1$ mouse strain commonly shows accelerated presbycusis (Shone et al. 1991) with hearing loss at about 4 weeks, prior to hair cell loss (Le Calvez et al. 1998a, b). Studies of these mice have shown different possible causes: one suggests that SL damage precedes hair cell loss initially in basal turn, with a reduction in endolymphatic $\mathrm{K}^{+}$concentration ( $\mathrm{Wu}$ and Marcus 2003). However, others report that the SG degenerates first 
(Riva et al. 2005, 2007). These differences may reflect strain variations in different facilities.

The SG consists primarily of afferent neuronal cell bodies with satellite cells surrounding them. The satellite cells express proteins indicative of oxidative stress, mitochondrial defects and apoptosis by 4 weeks of age (Donadieu et al. 2007; Riva et al. 2007).

The SL consists of five main types of fibrocyte embedded in extensive extracellular matrix in mice (Furness et al. 2009) and gerbil (Spicer and Schulte 2002). Type I fibrocytes are lateral to the SV, type II lateral to the spiral prominence epithelium, type III along the external edge of SL, type IV in the basilar crest region and type V are supra-strial (Spicer and Schulte 1991, 2002; Nakazawa et al. 1995; Ichimiya et al. 2000; Suko et al. 2000; Weber et al. 2001). Fibrocyte degeneration occurs in various mouse strains (Hequembourg and Liberman 2001; Wu and Marcus 2003), in labyrinthitis (Ichimiya et al. 1998), otitis media (Ichimiya et al. 1999), genetic hearing loss DFN3 (Minowa et al. 1999), noise exposure (Hirose and Liberman 2003) and otospiralin knock-outs (Delprat et al. 2005).

Mitochondrial degeneration in the SL, as in the SG, plays a crucial role; in a mouse model of DFN3, fibrocytes had fewer mitochondria (Minowa et al. 1999), and in mice exposed to a mitochondrial toxin, 3-nitropropionic acid (3-NP) (Okamoto et al. 2005), SL pathology was accompanied by hearing loss. Systemic administration of a caspase inhibitor prior to and during 3-NP administration suggested that caspasedependent apoptosis of fibrocytes takes place as a result of mitochondrial damage (Mizutari et al. 2008).

The present study was motivated by the possibility of attempting SL cell replacement therapy using CD/1 mice bred in our animal facility. We therefore have investigated the time course of degeneration of their cochlear structures, specifically: (1) the pattern of cell loss, (2) the ultrastructural signs of early pathology and (3) the extent of mitochondrial damage using structural quantification and visualization of the cytochrome oxidase system (Seligman et al. 1968, 1973; Perotti et al. 1983).

\section{MATERIALS AND METHODS}

\section{Animals}

$\mathrm{CD} / 1$ mice were bred and maintained in Keele University's Central Animal Facility. To avoid the strain from becoming significantly inbred, stock was refreshed periodically by introducing new mice from the suppliers (Charles Rivers). All animals were treated in accordance with the UK Animals (Scientific Procedures) Act of 1986, and the project was given approval by Keele University's ethical committee.

\section{Hair cell counts}

To determine the time course of hair cell loss, two animals each at 10, 15 and 20 weeks old were used to obtain cochleae for hair cell counts. Animals were given an overdose of sodium pentobarbitone (IP; Pentoject, Animalcare Ltd, York), decapitated, the bullae removed and opened to expose the cochleae. These were fixed by intralabyrinthine perfusion and subsequent immersion for $2 \mathrm{~h}$ in $4 \%$ paraformaldehyde (PFA) in $0.1 \mathrm{M}$ phosphate buffer (PB) at $\mathrm{pH} 7.4$, decalcified with $5.5 \%$ ethylenediaminetetraacetic acid (EDTA) containing $0.1 \%$ PFA in PB for 3-10 days and dissected into two to three portions using needles and iris scissors. They were then stained with 1:100 phalloidin-FITC in phosphate buffered saline (PBS) containing $0.2 \%$ Triton-X-100 for $1 \mathrm{~h}$, mounted onto slides and examined with a $\times 60$ objective lens with a 2-mm working distance on a BioRad MRC 1024 confocal microscope. Stacks of images were acquired along the length of the cochlea, with each image representing a square of $226 \times 226 \mu \mathrm{m}$. Hair cells were assessed quantitatively in the most complete dissection from each age; the others being used to confirm the general pattern. The number present was determined by identifying intact apical cuticular plate and stereocilia, and the number of gaps estimated to provide a total expected and so calculate a percentage survival per image. Where there was very substantial hair cell loss, numbers expected could not be estimated accurately from the large gaps, so the average obtained per image from the 10-week-old sample (where few were missing) was used as the expected value.

\section{Fixation and embedding for light and electron microscopy}

To evaluate other regions and to assess cellular condition at the electron microscopic level, mice of $0,2,3,5,10,15$ and 20 weeks old (four animals in each age group) were prepared for sectioning. Prior to preparation for electron microscopy, mice were tested for the presence or absence of hearing by eliciting an acoustic startle reflex by making a snap of two fingers directly above their cage. Whilst not quantitative, this gave some indication of hearing ability. Animals were anesthetised and the cochlea exposed as above. Each cochlea was fixed by perfusion with $2.5 \%$ glutaraldehyde (GTA) in $0.1 \mathrm{M}$ sodium cacodylate buffer containing $2 \mathrm{mM}$ calcium chloride ( $\mathrm{pH}$ 7.4) through the round window and a small hole made in the apex, and immersed in the same fixative for $2 \mathrm{~h}$. Cochleae were then washed in $0.1 \mathrm{M}$ sodium cacodylate buffer containing $2 \mathrm{mM}$ calcium chloride ( $\mathrm{pH} 7.4$ ), fixed in $1 \%$ osmium tetroxide in the same buffer for $1 \mathrm{~h}$ and decalcified in 5.5\% EDTA/0.1\% PFA solution for $3-4$ days at $4^{\circ} \mathrm{C}$. The decalcified 
cochleae were dehydrated in a graded series of ethanols $(70 \%, 80 \%, 90 \%, 100 \%$ and dry $100 \%)$ for $30 \mathrm{~min}$ in each concentration, infiltrated with mixtures of ethanol and Spurr resin followed by pure Spurr resin over a period of $8 \mathrm{~h}$ and polymerized in pure Spurr resin at $60^{\circ} \mathrm{C}$ for $36 \mathrm{~h}$.

Some cochleae from 52- $(n=2)$ to $72-(n=2)$ weekold $\mathrm{CD} / 1$ mice available from a separate study were evaluated for fibrocyte loss. These were fixed in $4 \%$ PFA, decalcified, dehydrated and embedded in LRWhite resin according to the methods described in Furness et al. (2009).

\section{Light microscopy and quantification of cell loss} with age

Two midmodiolar semithin sections $(1-2 \mu \mathrm{m})$ were cut from the embedded cochlea of each of the four animals from the 3- and 20-week-old groups. LR-white embedded cochlear sections from 72week-old mice from a previous project were also used for qualitative assessment of cell survival. To quantify the number of fibrocytes of each type, the number of cells in the SV the number of capillaries, and the survival of SG neurones in the 3and 20-week mice, the sections were stained with toluidine blue and a montage of images acquired of the basal lateral wall from both sides of the coil, using a $\times 40$ objective on a Leitz Dialux light microscope (LM) fitted with an Infinity digital camera. After assembling the lateral wall montage, the number of cell nuclei in each category, and the number of patent capillary profiles in each area was counted. This method thus analyses a relatively large but equivalent area in all samples representing the lower basal half turn of the cochlea. A single image of the SG was also obtained from one section from each mouse, a $75 \times 75 \mu \mathrm{m}$ square was placed approximately over the centre at low magnification, then enlarged, and the number of ganglion-cell nuclei within the square was counted. To avoid overcounting or undercounting, only cells that were fully in the square or bisected by the right and top sides were counted, whilst those bisected by the left and bottom sides of the square were not counted.

Transmission electron microscopy. To examine the SL, SV, SG and organ of Corti at the ultrastructural level by transmission electron microscopy (TEM), ultrathin midmodiolar sections $(120 \mathrm{~nm})$ were cut, stained in $2 \%$ ethanolic uranyl acetate $(20 \mathrm{~min})$ and lead citrate $(2 \mathrm{~min})$ and examined using a JEOL JEM-1230 transmission electron microscope operated at $100 \mathrm{kV}$.
Mitochondrial degeneration. To assess degeneration of mitochondria in the different types of fibrocyte and in SG in aging CD/1 mice (3, 5 and 10 weeks old; $n=3$ from each age group), random micrographs were taken of the different types of fibrocyte and regions of SG and a rating scale was used to designate the extent of mitochondrial damage: $1=$ normal, $2=$ minimal damage with small white holes, $3=$ more damage with large area of white holes, $4=$ approximately half of the area degenerated with larger white holes, and $5=$ maximal damage, mitochondria expanded dramatically.

Diaminobenzidine cytochrome oxidase reaction product in mitochondria. Because mitochondrial damage was most evident in fibrocytes, mitochondrial cytochrome oxidase reaction was assessed in them from 3- $(n=2)$ and 10- $(n=2)$ week-old $\mathrm{CD} / 1$ mice. Animals were anaesthetised as above, decapitated, the bullae removed and opened and the protocol of Perotti et al. (1983) employed. Each cochlea was fixed by perfusion with $1 \%$ PFA and 2\% GTA in $0.1 \mathrm{M}$ sodium cacodylate buffer containing $2 \mathrm{mM}$ calcium chloride ( $\mathrm{pH} 7.4$ ) through the round window and a small hole made in the apex and immersed in the same fixative for $15 \mathrm{~min}$. The cochleae were then washed overnight at $4^{\circ} \mathrm{C}$ in $0.1 \mathrm{M}$ sodium cacodylate buffer, followed by three changes in the same buffer over a period of $4 \mathrm{~h}$, dissected partially to expose the cochlear spiral and incubated in $10 \mathrm{mg}$ of $3,3^{\prime}-$ diaminobenzidine tetrahydrochloride (DAB, SigmaAldrich) in $10 \mathrm{ml}$ of $0.05 \mathrm{M}$ tris-HCl buffer ( $\mathrm{pH} 7.4$ ) at $37^{\circ} \mathrm{C}$ in a water bath for $3 \mathrm{~h}$ (every $30 \mathrm{~min}$, the $\mathrm{DAB}$ medium was replaced with freshly prepared DAB solution). The cochleae were then washed in $0.05 \mathrm{M}$ tris-HCl buffer, fixed in $2.5 \%$ glutaraldehyde in $0.1 \mathrm{M}$ sodium cacodylate buffer for $2 \mathrm{~h}$, washed in $0.1 \mathrm{M}$ sodium cacodylate buffer, fixed in $2 \%$ osmium tetroxide in sodium cacodylate buffer for $2 \mathrm{~h}$, and washed in the same buffer. They were then dehydrated in ethanol and embedded and polymerised in Spurr resin for TEM. Midmodiolar ultrathin sections were cut and stained in lead citrate for $2 \mathrm{~min}$ and examined using the JEOL JEM-1230 electron microscope operated at $100 \mathrm{kV}$.

\section{RESULTS}

Location and identification of the different cochlear regions

A LM cross section of the cochlear duct in the basal turn of a 3-week-old cochlea, comprising scala media, SG and lateral wall, and the location of different fibrocyte types in the latter, is shown in Figure 1 for orientation purposes. The lateral wall consists of SV and SL the latter including the basilar crest and spiral prominence. The different fibrocyte types in these 

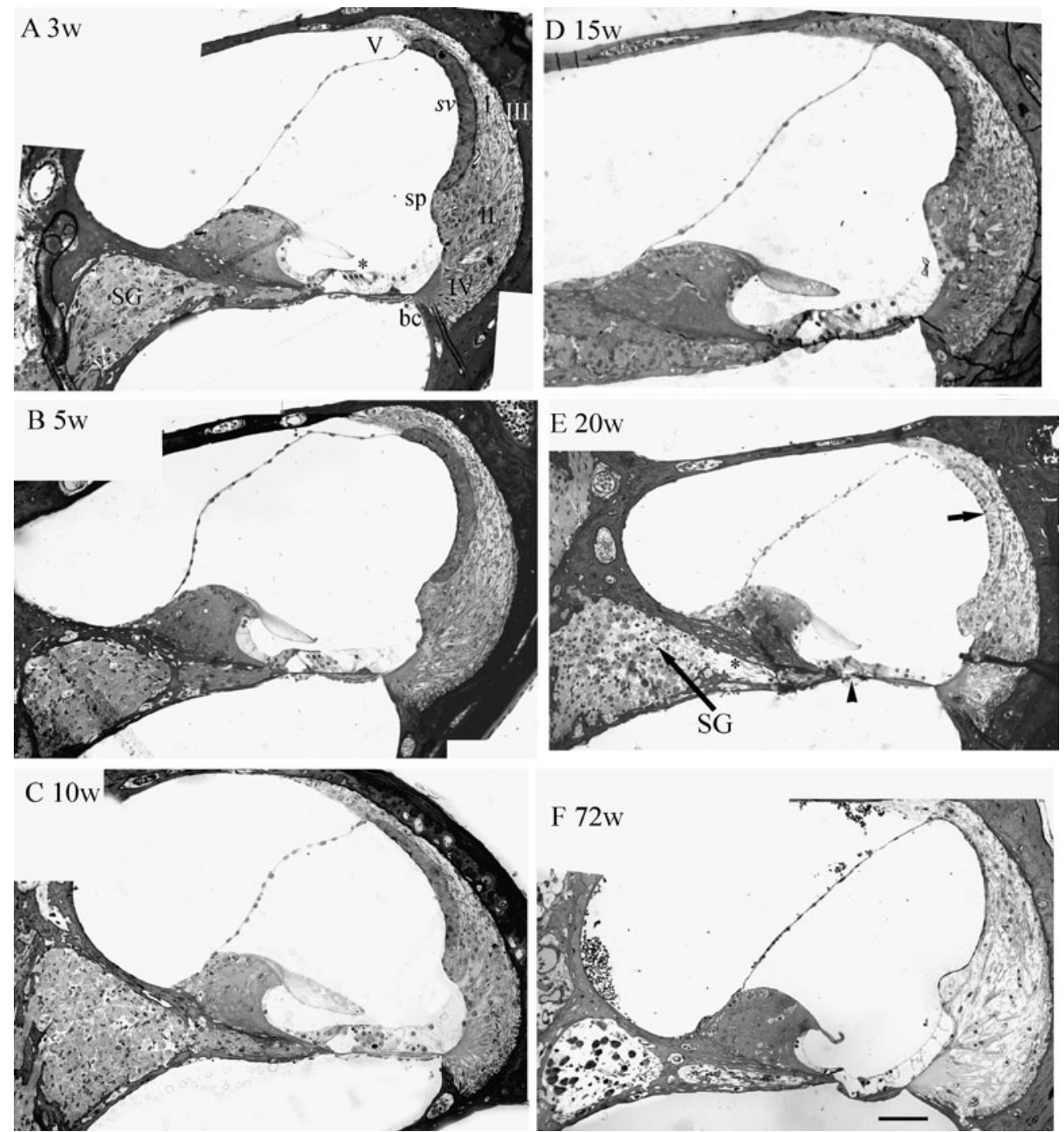

FIG. 1. Radial toluidine blue-stained sections of the basal turn cochlear duct at various ages (3-72 weeks). A The 3-week section illustrates the organ of Corti (asterisk) spiral ganglion $(S G)$ and lateral wall, the latter consisting of spiral prominence $(s p)$, SV $(s v)$, basilar crest $(b c)$ and SL with five distinct fibrocyte regions (I, II, III, IV and V). Note that type III cells run along the boundary of the SL with the bony wall. The remaining cross sections (B-E) of 5-, 10-, 15- and 20-week-old mice show progressive changes with age. At 20 weeks, regions of the lateral wall are lighter stained (arrow), there is loss of peripheral processes projecting from the SG to the hair cells (asterisk) and total loss of hair cells (arrowhead). F A 72-weekold section shows substantial loss of fibrocytes in the SL, degeneration of the organ of Corti and SG. Note, however, that the extracellular matrix of the $\mathrm{SL}$ is preserved. Bar=50 $\mu \mathrm{m}$.

locations have been described previously at the EM level for the CD/1 mouse (Furness et al. 2009) and we have used the same criteria here for identification.

Equivalent images are shown for 5-, 10-, 15-, 20- and 72-week-old cochleae (Fig. 1B-F). By 20 weeks the organ of Corti was substantially damaged. The SV had a normal thickness even at 20 weeks, but appeared lighter stained in some samples. The SL appeared to have a reduced cell density and the SG showed evidence of loss of peripheral processes as they approached the organ of Corti. By 72 weeks, significant degeneration had occurred in all tissues around the cochlear duct, in the organ of Corti, SG and SL, although the extracellular matrix in which the fibro- cytes are normally embedded appeared still to be present. The LM images did not show substantial qualitative changes before 20 weeks, although the mice clearly became deaf or nearly so by 20 weeks. Acoustic startle reflexes were present in all the mice except 2 at 20 weeks, but reduced hearing (in terms of limited reaction to the clicking sounds made above the cage) was noted in one out of four animals at 5 and 10 weeks, two out of four at 15 weeks and the remaining two out of four at 20 weeks, indicating a progressive decrease in hearing ability over this period. This prompted us to evaluate the time course of degenerative changes by cell counts and electron microscopy. 


\section{Quantitative analysis of cell losses}

Hair cell counts (Fig. 2) from phalloidin-stained surface preparations showed very few missing cells by 10 weeks but progressive loss subsequently, from the basal end. By 20 weeks, more than half of the outer hair cells in all three rows, and significant numbers of inner hair cells, were missing.

To determine how much fibrocytes loss occurs, and which types were most affected, quantitative analysis of the number of each of the different types of fibrocytes was carried out in 3 and 20 weeks old CD/1 mice ( $n=4$ per group). At 3 weeks, the SL appeared normal at the LM level. Between the two time periods, there was a reduction in mean number of all of the fibrocyte types except type $\mathrm{V}$, with greatest percentage reduction in type IV (Fig. 3). Statistical analysis using a Wilcoxon's sign rank test indicated that the reduction in type I fibrocytes was not significant $(P>0.05)$, but it was significant for types II, III and IV $(P<0.05)$. The SG cells were also counted in the central portion of the ganglion, with no evidence of cell loss despite the loss of peripheral processes noted above (Fig. 3; Wilcoxon's sign rank test, $P>0.05$ ).

We also analysed other structures in the lateral wall by counting cells and capillary profiles. The number of cells in the three layers of the SV (basal cells, intermediate cells and marginal cells) did not change significantly, nor did the number of capillary profiles in either the SL or the SV (Fig. 3).

\section{Ultrastructural observations}

LM observations indicated that all except type $\mathrm{V}$ fibrocytes consistently begin to degenerate between 3 and 20 weeks, but subtle changes will not be detected by this method. We therefore evaluated the ultrastructure of hair cells, SL, SV and SG at 0, 2, 3, 10, 15 and 20 weeks. Since hair cell damage or loss appears first in the high-frequency region, we examined mainly the basal locations of the $\mathrm{CD} / 1$ cochlea, but where damage was evident more apically, we comment on that also.

Zero- to three-week-old mice. At 0 weeks old, fibrocytes were undifferentiated and showed no evidence of damage (data not shown). At 2 weeks old, fibrocytes could be distinguished from each other and had virtually adult morphology. They showed minor evidence of mitochondrial damage whilst minimal changes were noted in the organ of Corti, although some vacuolization was occasionally seen in outer hair cells. Overall SL, SV, SG and organ of Corti were relatively normal (data not shown). In 3-week-old mice, the organ of Corti (Fig. 4A) again appeared normal. In SL mitochondria showed greater, and
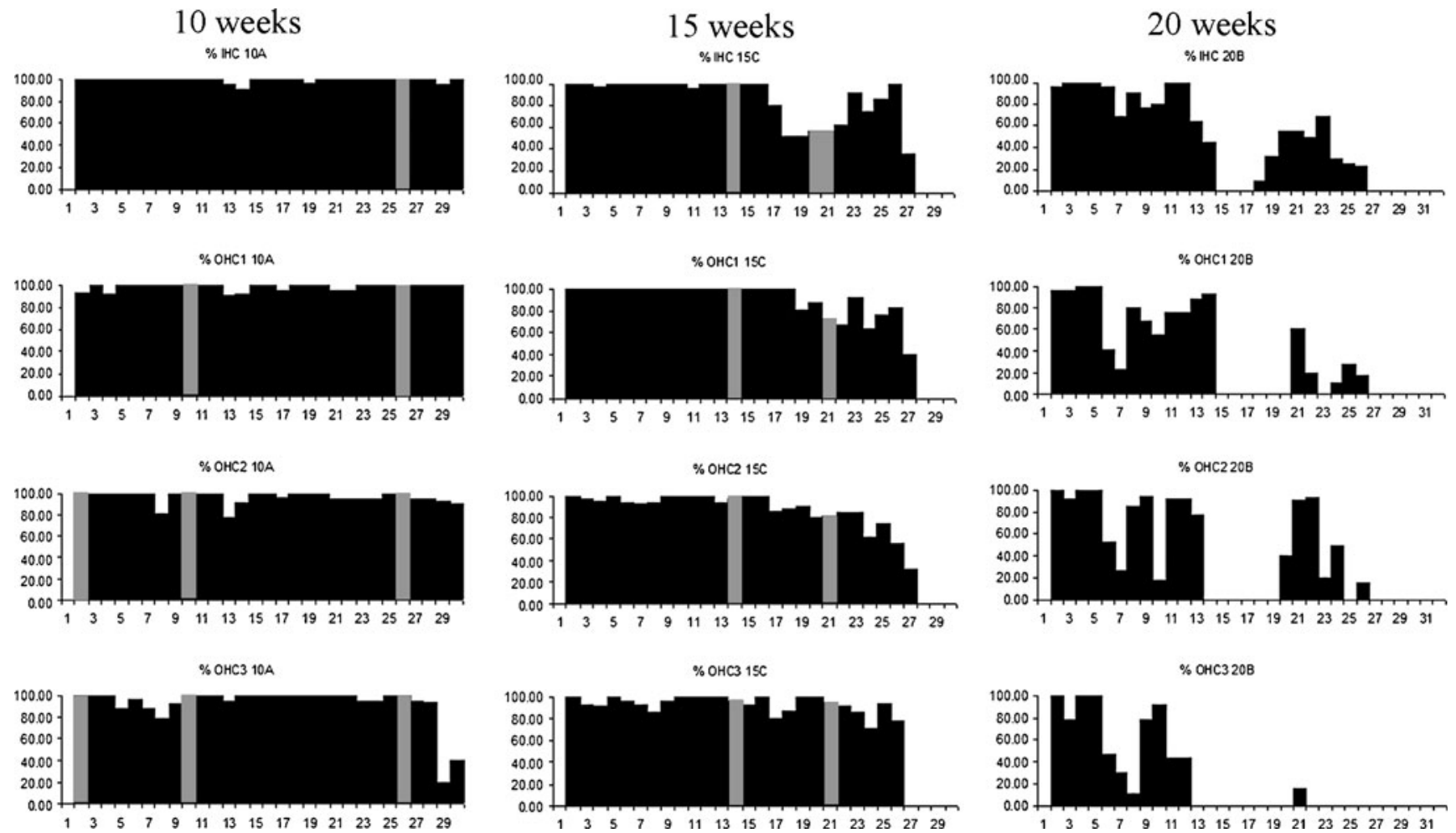

FIG. 2. Cytocochleograms at 10,15 and 20 weeks old; each bar represents a count from one of a series of images taken sequentially along the organ of Corti from apex (bin 1) to base. Grey bars are estimates from smaller areas or adjacent images where the organ of Corti was damaged by dissection or obscured. Note the virtually intact organ of Corti at 10 weeks, with progressively larger loss of hair cells from the basal turn to the apex in all rows from 15 to 20 weeks. (Labels $10 \mathrm{~A}, 15 \mathrm{C}$ and $20 \mathrm{~B}$ refer to the specific cochlea chosen for counting of the four examined at each age). 


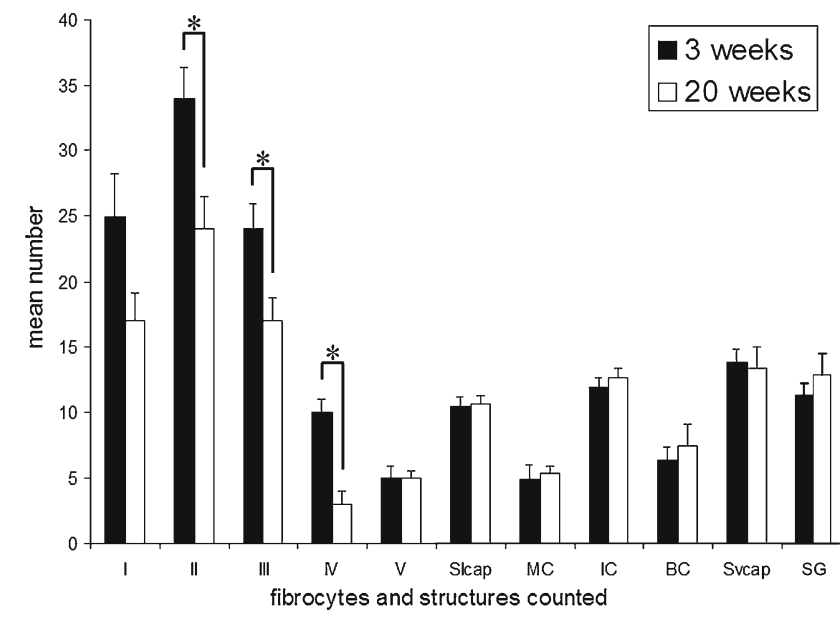

FIG. 3. Histograms showing the mean number of nuclei of the five different types of fibrocyte, mean number of capillary profiles in SV and SL (SVcap and SLcap, respectively), mean number of marginal cell (MC), intermediate cell (IC) and basal cell ( $B C$ ) nuclei and mean number of SG neurones per $75 \times 75 \mu \mathrm{m}$ area in 3- and 20-week-old CD/1 mice. The mean number of types I, II, III and IV fibrocyte is less in the 20-week-old mice compared with the 3-week-old ones, but there is no difference in the type $V$ fibrocyte number. Differences that were significant $(P<0.05)$ on a Wilcoxon's sign rank test are indicated by asterisks. There are no significant differences in number of capillaries in the SV or SL or cells in SV or SG. Bars indicate the standard error of the means.

varying, degrees of degeneration in all types of fibrocyte in all samples, and to a lesser extent in the SV (Fig. 4B-F). The SG appeared undamaged in one sample (Fig. 5A), damaged to only a minor extent in a second (Fig. 5B) and in a third showed evidence of extensive swollen Golgi and endoplasmic reticulum cisternae in the neurons but little damage to mitochondria (Fig. 5C). Satellite cells in this sample showed vacuolization.

To test whether mitochondrial damage was an artefact of fixation, we also examined two other strains of mice fixed and embedded using the same method. Fibrocytes were examined from young adults (34 weeks) of C57BL/6 (data not shown) and C3HeB/ FeJ (Fig. 6). Neither showed evidence of mitochondrial damage.

Five-week-old mice. In 5-week-old mice, TEM analysis suggested that the organ of Corti was normal (Fig. 7A). The SV showed an increased degree of degenerating mitochondria in some animals compared with 3-week mice (Fig. 7B) although it was normal in others. In fibrocytes in basal locations of all animals, however, there was evidence of cytoplasmic degeneration in all types in the form of vacuoles that were also found associated with mitochondria (Fig. 7D, E and G), and nuclear disruption in some of the type V cells (Fig. 7G). Some of the type IV fibrocytes showed a greater degree of degeneration as manifested by remnants of disintegrating cytoplasm and nuclei (Fig. 7F). A few type IV fibrocytes in such a late stage of degeneration were also found in the apical turn of the cochlea (data not shown). The SG was normal in two out of three mice, and in the third, mild evidence of cytoplasmic extraction was noted around the margins of $\mathrm{SG}$ neurones (data not shown). Mild damage was noted in mitochondria of the neurones.

Ten-week-old mice. Mild to extensive cytoplasmic degeneration was noticed in the hair cells of the basal turn of 10-week-old mice (Fig. 8A) whilst the hair cells in the apical location appeared normal. Damage took the form of vacuolization and cellular distortion, but did not appear to involve specifically the mitochondria as a primary feature. The SV showed little evidence of degeneration but some mitochondrial swelling was observed (Fig. 8B). At this age, more substantial changes were observed in all of the different types of fibrocytes in the basal turn. The nuclei of some of the fibrocytes appeared to have reduced chromatin, the nucleoplasm appearing less dense, the cell body appeared shrunken and distorted and the cytoplasm less dense in type I and type II especially (Fig. 8C-G). The type II fibrocytes also had more pronounced plasma membrane folding (compare Fig. 8D with Fig. 7D). Although spaces remained in the type IV area, the fibrocytes were reduced to remnants of disintegrating cytoplasm and nuclei (Fig. 8F). Moderate to severe cytoplasmic vacuolization was noticed in the type $\mathrm{V}$ fibrocytes which, however, retained some normal appearing cytoplasm and mitochondria (Fig. 8G). Despite the degeneration and shrinkage of fibrocytes, extracellular matrix was still present and appeared normal around all of them (Fig. 8C-G).

The SG again appeared normal in one sample, mildly disrupted in a second and with more major disruption in the third (Fig. 9), with similar pathology to that described previously at 3 and 5 weeks although with greater evidence of mitochondrial pathology in neurones and satellite cells (see below).

Fifteen-week-old mice. In 15-week-old mice, both outer hair cells and fibrocytes showed more extensive degeneration (Fig. 10). In the basal locations of the cochlea, outer hair cell damage and loss was evident and Deiters' cells were seen extending into the space previously occupied by the outer hair cells (Fig. 10A). The hair cells in the apical turn of the cochlea did not show any substantial changes. SV in the basal turn at this age showed localised areas of damage, but mostly normal morphology (Fig. 10B). In the basal locations, empty spaces were seen in the type I fibrocyte area (Fig. 10B) and in the basilar crest area (Fig. 10C), suggesting loss of types I and IV fibrocytes, respectively. The cell bodies of type $\mathrm{V}$ fibrocytes contained large vacuoles with mitochondria in them, and there was evidence of degeneration of the large 

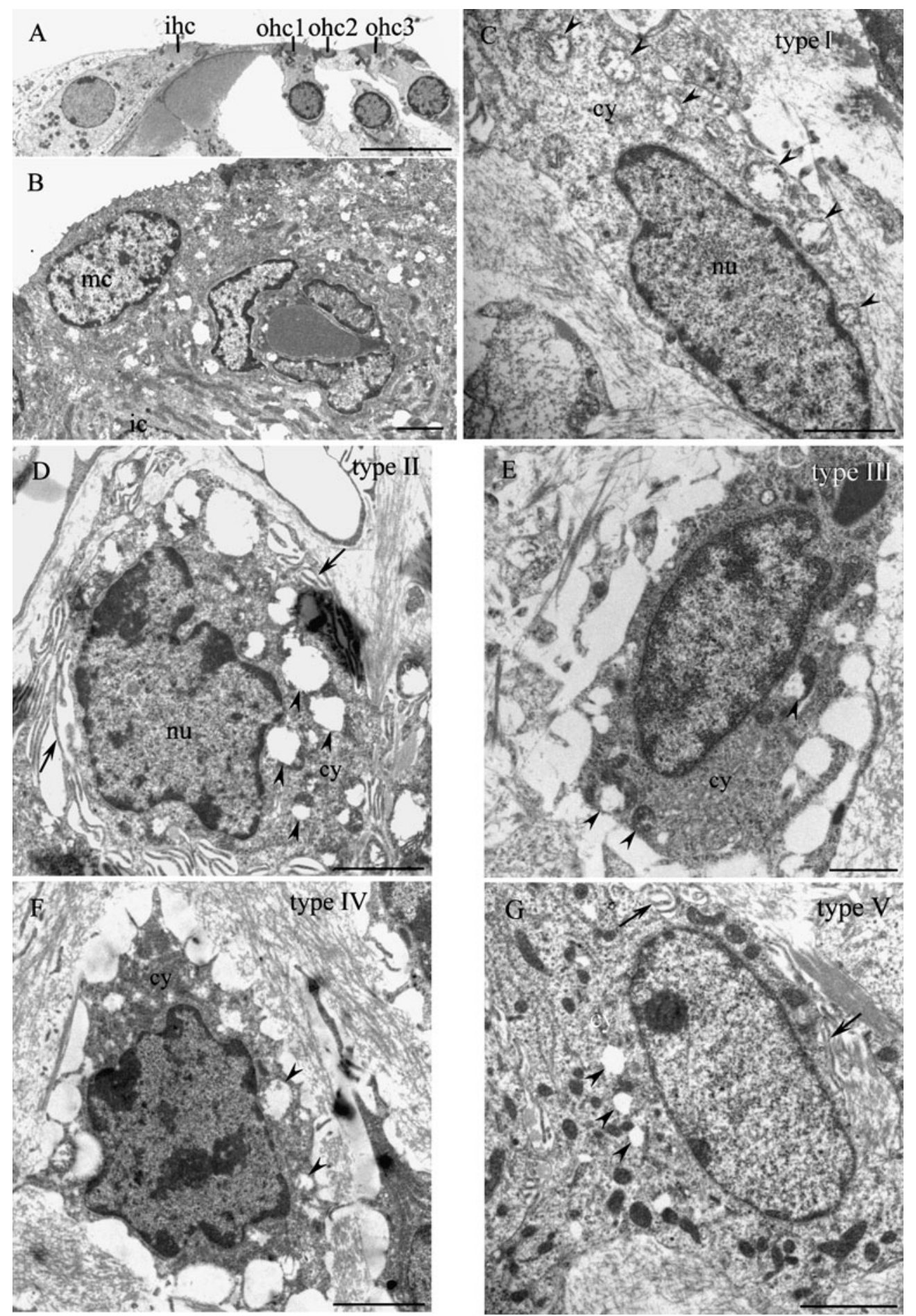

FIG. 4. TEM of radial sections of mice at 3 weeks old. A The organ of Corti has a normal appearance with the inner hair cell (ihc) and three rows of outer hair cells (ohc1, ohc2 and ohc3) visible. B The SV is relatively normal but there is evidence of swollen mitochondria; marginal cell ( $m c$ ), intermediate cell (ic). C-G In all fibrocytes, a varying number of mitochondria (arrowheads) appear swollen and distorted to different degrees, with reduced cristae, but the nuclei $(n u)$ and cytoplasm $(c y)$ appear normal, with the exception of some evidence of white spaces in addition to the mitochondrial swelling in type IV cells. Note the characteristically extensive plasma membrane folding (arrows) in type II and $\mathrm{V}$ cells. Bar= $10 \mu \mathrm{m}(\mathbf{A})$; bar=2 $\mu \mathrm{m}(\mathbf{B}, \mathbf{C}, \mathbf{E}, \mathbf{F}$ and $\mathbf{G}) ;$ bar $=1 \mu \mathrm{m}(\mathbf{E})$.

processes extending to the edge of the scala vestibuli (Fig. 10D). Extracellular matrix was still present in apparently normal distribution as there were large fibres adjacent to gaps that generally were devoid of material except for cell remnants (Fig. 10B-D). The
SG showed similar degrees of pathology to the worst observed at 10 weeks (data not shown).

Twenty-week-old mice. In the 20-week-old mice, outer hair cells were damaged and lost in basal locations, inner hair cells were distorted and 

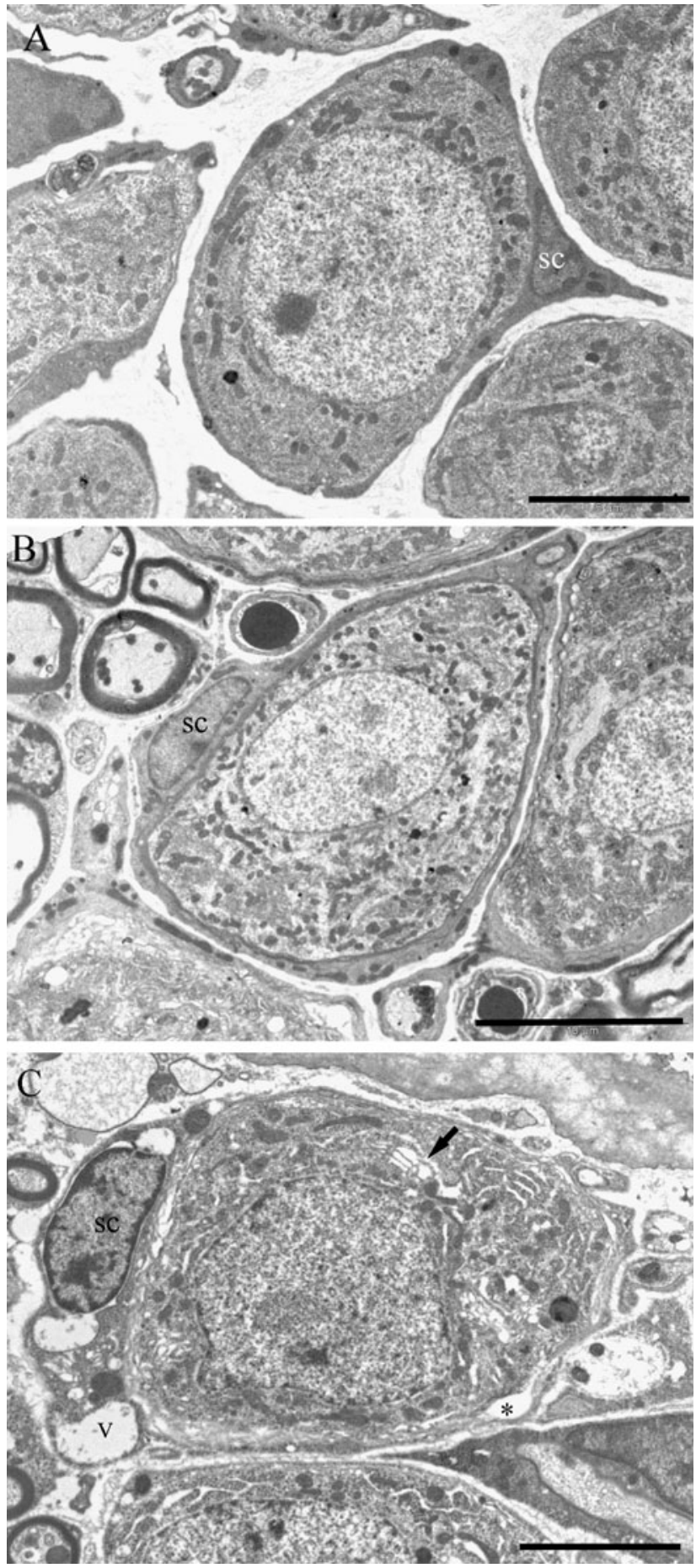

FIG. 5. TEM of SG in 3-week-old mice. Three examples are shown (A-C) with increasing amounts of abnormality. The example in $\mathbf{A}$ shows no evidence of degeneration, whereas mild cytoplasmic disruption is visible in $\mathbf{B}$, and swollen cisternae of endoplasmic reticulum and Golgi body (arrow) are visible in $\mathbf{C}$. The satellite cells ( $S C$ are all normal except in $\mathbf{C}$ where vacuolization has occurred $(v)$, and there is a small degree of separation of the myelin sheath from the neuron in places (asterisk). Bar $=5 \mu \mathrm{m}$ (A and $\mathbf{C}) ; \operatorname{bar}=10 \mu \mathrm{m}(\mathbf{B})$.

supporting cells surrounding the inner hair cell were also damaged (Fig. 11A); outer hair cell damage and loss was also observed in the apical locations (data not shown). The SV showed some localised areas of

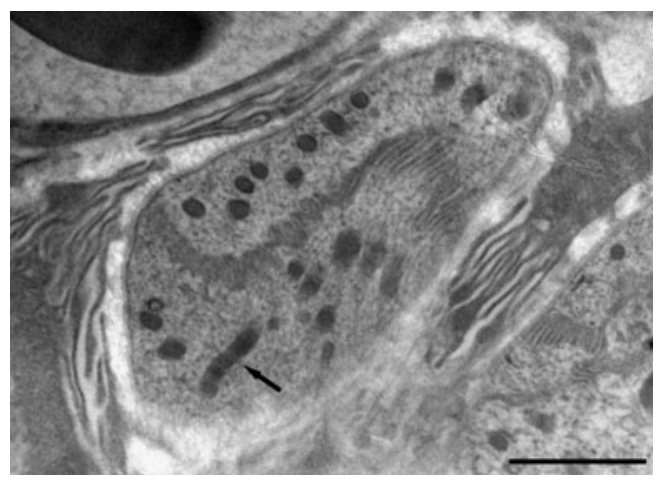

FIG. 6. TEM of 4-week $\mathrm{C} 3 \mathrm{HeB} / \mathrm{Fe}$ J mouse type II fibrocyte prepared in the same way as the $C D / 1$ mice. Mitochondria appear to be well preserved (e.g. arrow), indicating that the mitochondrial damage in the $C D / 1$ mice is not a fixation artefact. Bar=2 $\mu \mathrm{m}$.

damage (Fig. 11B), but substantial regions of normality. In the basal locations, some type I fibrocytes were lost and the remaining ones had very few organelles (Fig. 11C); some type III fibrocytes were lost and the cytoplasm of the remaining ones was substantially reduced (Fig. 11D). Gaps were seen in the extracellular matrix of the basilar crest region due to the loss of type IV fibrocytes (Fig. 11E), and the supra-strial region was reduced in extent with type $\mathrm{V}$ cells, though present, appearing to be further degenerated (Fig. 11F). The SG neurons showed more evidence of dilated cisternal membranes and separation from satellite cells, though the latter appeared relatively normal (data not shown).

Fifty-two-week-old mice. In the 52 week-old $\mathrm{CD} / 1$ mice, no hair cells were observed in the basal turn (Fig. 12A). The SV of upper basal turn showed some vacuolization in some of the animals, whilst in the lower basal turn it was reduced in thickness with fewer cells remaining (Fig. 12B). Many fibrocytes were missing but a few remaining cells were located in the regions corresponding to type I, II, III and V; virtually all type IV cells had degenerated. The extracellular matrix formed a framework around the gaps that resembled the matrix of younger stages (Fig. 12C-F). The SG also had few cells left.

\section{Quantitative changes in mitochondrial damage}

The ultrastructural data provided good evidence that degenerative changes occur in fibrocytes with age prior to substantial or consistent damage in other tissues. The most obvious changes were to mitochondria, although vacuolization also occurred (the latter potentially caused by extreme mitochondrial swelling) and eventual loss of cells. To evaluate further, the extent of degeneration at different stages, mitochondrial damage was assessed quantitatively by determining the proportion of mitochondria showing one of five different 

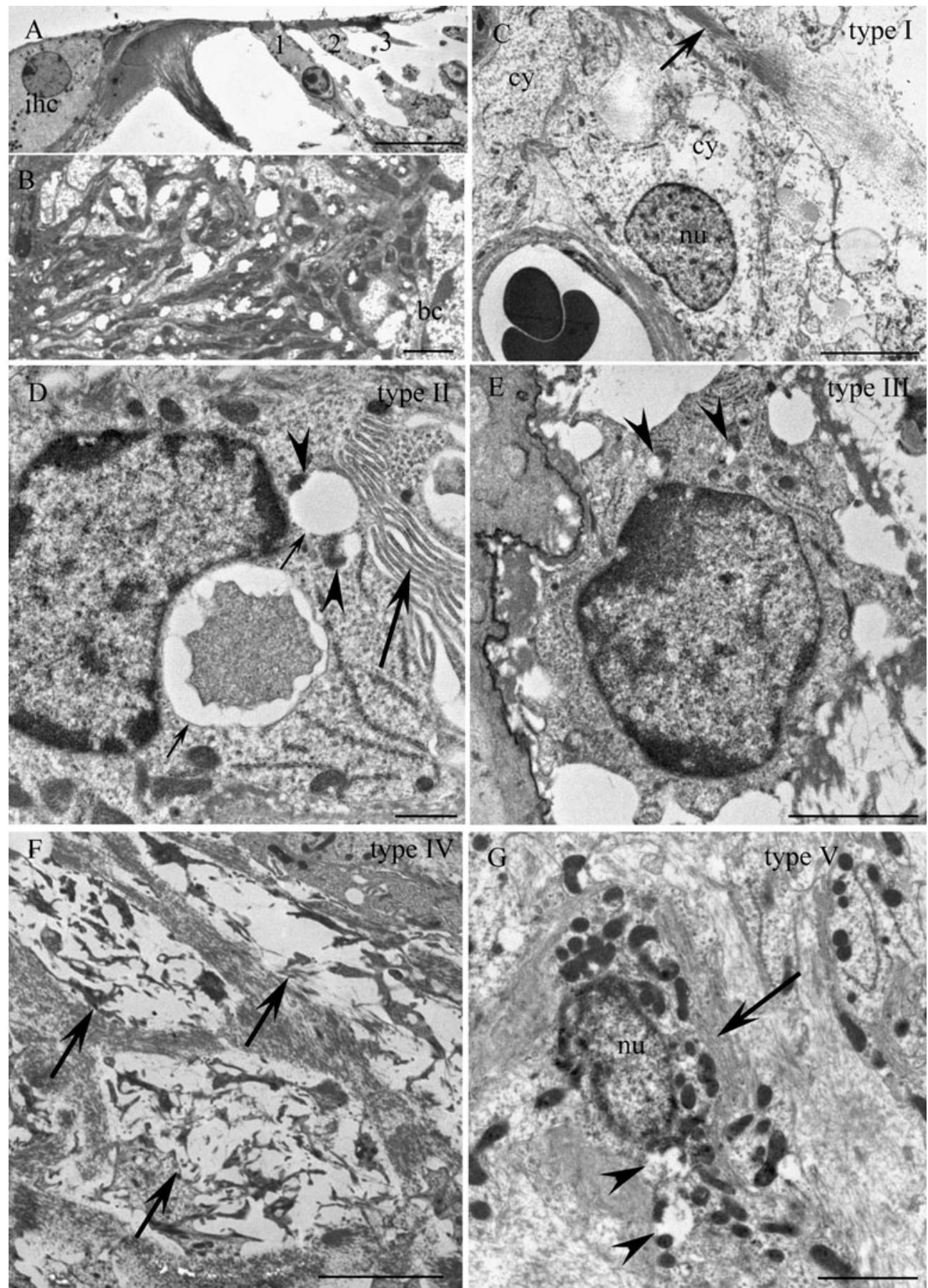

FIG. 7. TEM of radial sections of mice at 5 weeks old. A The organ of Corti still appears normal with inner hair cell (ihc) and three rows of outer hair cells (1, 2 and 3). B The SV shows increased evidence of mitochondrial swelling in some but not all of the animals investigated; basal cell (bc). C The cytoplasm of type I cells contains fewer organelles and is of lower density than preceding stages, but the nucleus (nu) appears normal; note the collagen fibres (arrow). D Type II cells with characteristic plasma membrane folding (large arrow), contain vacuoles of different sizes (small arrows) and some of the vacuoles are associated with mitochondria (arrowheads). E Vacuoles associated with mitochondria (arrowheads) in the cytoplasm of a type III cell. F Disintegrating type IV cells (arrows) with remnants of cytoplasm and nucleus. G The type V cell with normal plasma membrane folding (arrow) contains large vacuoles associated with mitochondria (arrowheads) and the nucleus (nu) is disrupted. Bar= $10 \mu \mathrm{m}(\mathbf{A}$ and $\mathbf{D}) ; \operatorname{bar}=5 \mu \mathrm{m}(\mathbf{C}$ and $\mathbf{F}) ;$ bar=2 $\mu \mathrm{m}(\mathbf{B}, \mathbf{E}$ and $\mathbf{G})$.

categories of damage in 3-, 5- and 10-week-old mice (Fig. 13). This analysis revealed that even at 3 weeks, less than half the mitochondria were considered normal in all the different fibrocyte types. Types III and IV fibrocytes showed the least proportion of normal mitochondria, types I and $\mathrm{V}$ the most.

After 5 weeks, the proportion of normal mitochondria had decreased in types I, II and V fibrocytes, 


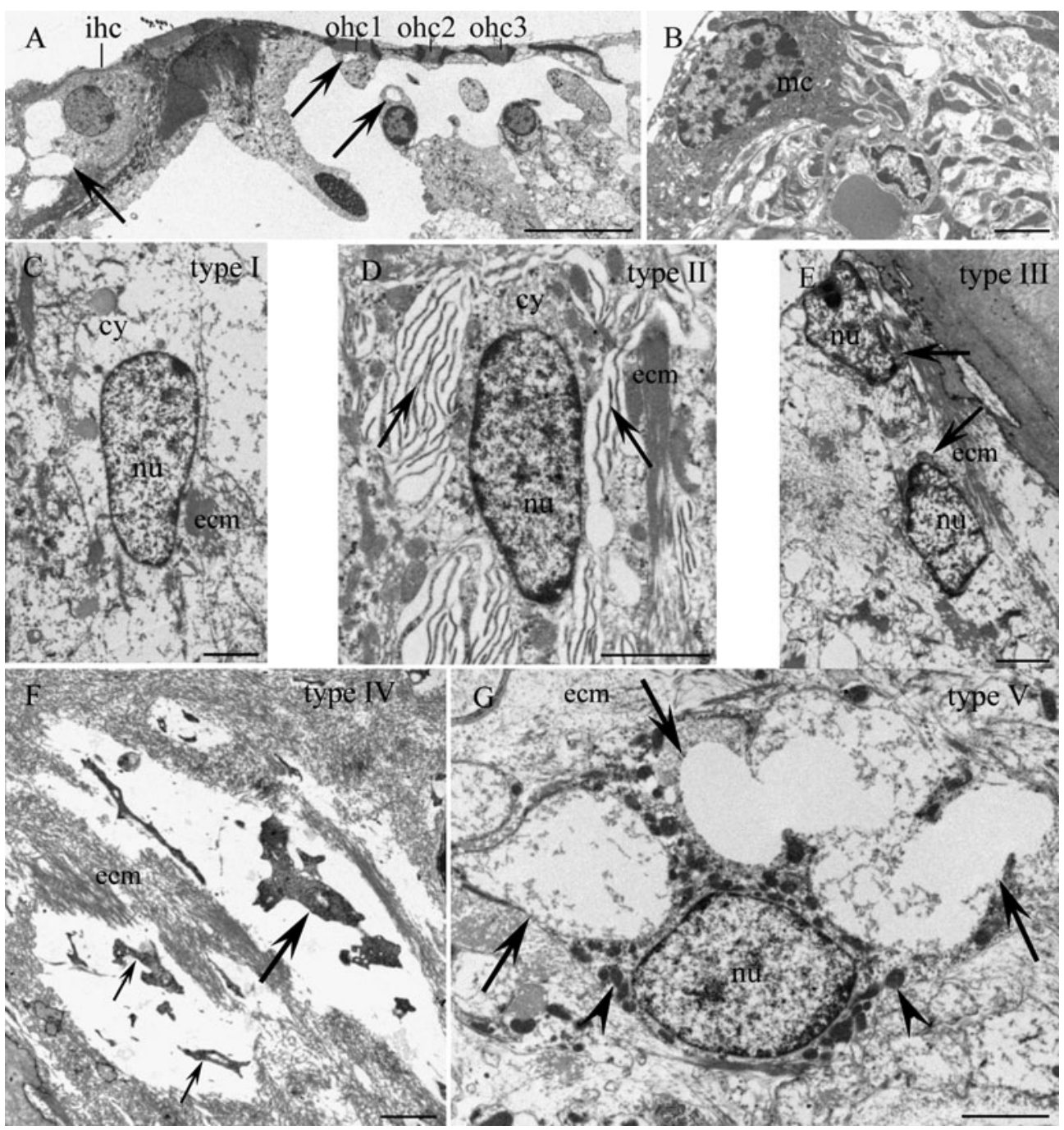

FIG. 8. TEM of radial sections of mice at 10 weeks old. A Radial section of an organ of Corti with inner hair cell (ihc) and three rows of outer hair cells (ohc1, ohc2 and ohc3). Vesiculation is evident in the cytoplasm (arrows) of the inner hair cell (ihc) and first row of outer hair cells (ohc1). B The SV retains a similar level of damage in some mice as at 5 weeks; marginal cell ( $m c)$. (C, D and E) The nuclei (nu) of types I, II and III fibrocyte have less chromatin and the cell bodies appear shrunken, especially type III (E, arrows), containing much thinner cytoplasm and very few mitochondria. Type II fibrocytes additionally have more pronounced membrane folding (D, arrows). $\mathbf{F}$ Large spaces previously occupied by type IV fibrocytes contain remnants of disintegrating cytoplasm (small arrows) and nucleus (large arrow). G Type V fibrocytes show severe vacuolization in the cytoplasm (arrows) but retain many normal mitochondria (arrowheads). Extracellular matrix (ecm) fibres were found in all fibrocyte locations and appeared normal. Bar=5 $\mu \mathrm{m}(\mathbf{A})$; $\operatorname{bar}=2 \mu \mathrm{m}(\mathbf{B}-\mathbf{G})$.

whilst the proportions showing a small level of damage (category 2) had increased. Little change was noted in types III and IV although the proportion of heavily damaged mitochondria (category 5) had increased slightly in all fibrocytes.

After 10 weeks, a clear decrease in normal mitochondria was seen in all fibrocyte types, with between $5 \%$ and $15 \%$ considered normal, the most in type $\mathrm{V}$ fibrocytes. Most of the damaged mitochondria showed relatively mild disruption (category 2 ).

By contrast, mitochondrial damage was absent in hair cells and much less prominent in the SG. Counts in the latter showed that few defective mitochondria were detected in satellite cells or neurons until week 10, with a minor increase in mitochondrial degeneration being noted in the neurons (Fig. 13) although substantially less than in SL. A statistical test of the change in proportion of normal mitochondria between weeks 3 and 10 was performed using the Wilcoxon's sign rank test. For pooled fibrocyte data, the proportion of normal mitochondria decreased significantly $(p<0.001$; $n=15)$ whereas for pooled SG-satellite cell data, there was no significant change $(p>0.05 ; n=6)$.

Cytochemistry of diaminobenzidine cytochrome oxidase reaction product in mitochondria of fibrocytes

In an effort to determine whether swollen mitochondria were dysfunctional, the cytochrome oxidase 


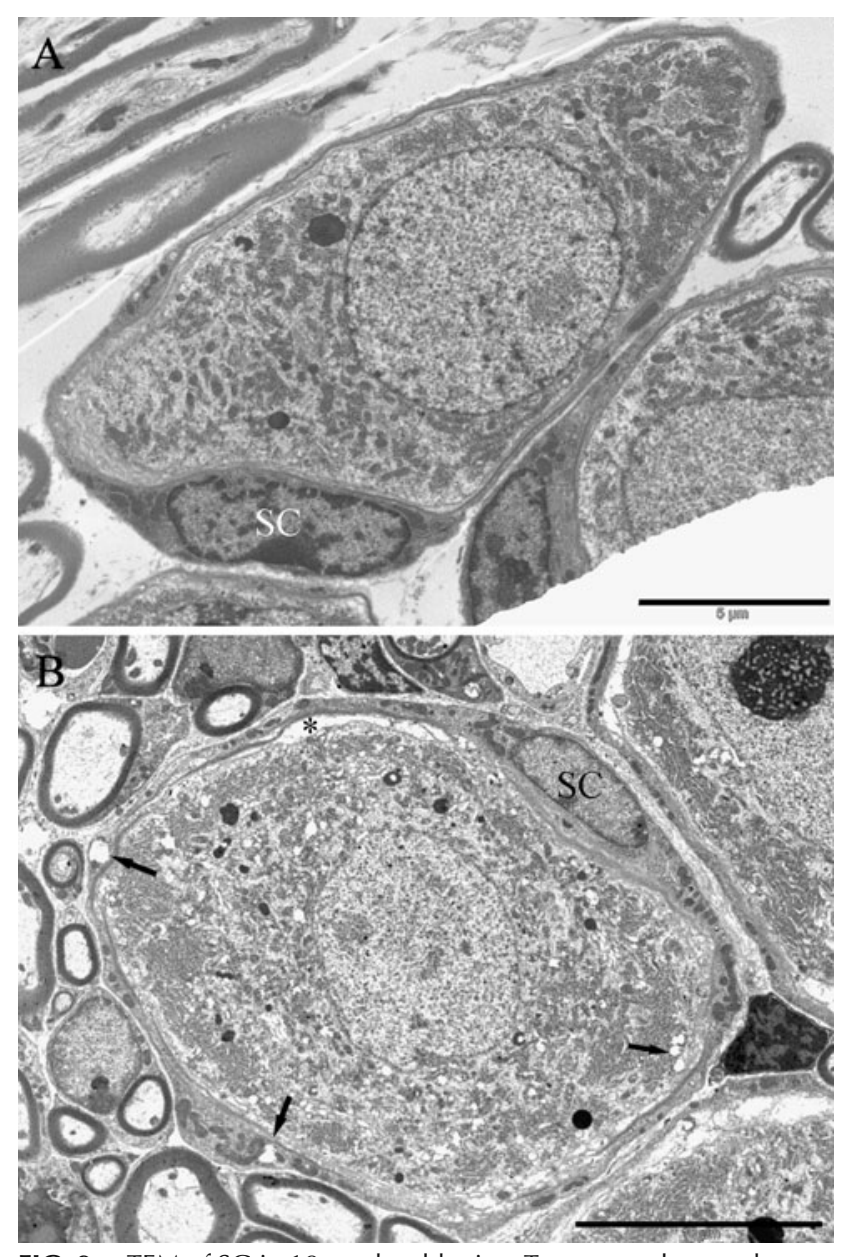

FIG. 9. TEM of SG in 10 weeks old mice. Two examples are shown. A illustrates a normal SG neurone, as was observed in two samples, whilst B illustrates the one sample with evidence of degeneration, in the form of swollen mitochondria (arrows) that are visible in the satellite cells $(S C)$ and neurons, and separation of the myelin sheath from the neuronal body (asterisk). Bar=5 $\mu \mathrm{m}(\mathbf{A})$; bar $=10 \mu \mathrm{m}$ (B).

reaction was tested histochemically. This reveals enzyme function in mitochondria via a direct reaction with diaminobenzidine. Qualitatively, most mitochondria, even damaged ones, showed evidence of retained enzymatic activity but damaged mitochondria appeared to have weaker reaction product than normal ones (Fig. 14).

\section{DISCUSSION}

The main aim of this study was to establish the sequence of degeneration of cochlear structures in $\mathrm{CD} / 1$ mice bred in our animal facility, with the ultimate aim of using this model for attempts at a cell replacement strategy. The data suggest that SL fibrocytes consistently begin to degenerate with changes in mitochondria before 3 weeks postnatal, whilst damage is not consistently seen in other major regions. The SG does show early degenerative changes in line with other reports (Riva et al. 2007) but not in all samples. Such changes include a small degree of mitochondrial degeneration, compared with SL, in the neurons and satellite cells, but also swollen Golgi and endoplasmic reticulum cisternae in the neurons. These changes are variable over the first 10 weeks, unlike the fibrocyte damage, as the SG can appear ultrastructurally normal at week 10, with no obvious cell loss even at 20 weeks. Similarly, the SV sometimes shows evidence of early pathology, but it too is variable and there is no evidence of cell losses before 20 weeks.

Although we have not investigated blood flow or the three-dimensional organisation of the capillary network we found no evidence of reduced numbers or occlusion of capillaries by 20 weeks to suggest alterations in microvasculature that could cause the progressive damage.

All the fibrocytes show mitochondrial changes, a feature not detected by LM. The possibility that this mitochondrial damage is a fixation artefact was ruled out by checking other strains of mice fixed with the same method as that used here. There was no evidence of mitochondrial damage in fibrocytes in young adult C57BL/ 6 or $\mathrm{C} 3 \mathrm{HeB} / \mathrm{FeJ}$ mice. Thus, the mitochondrial damage appears to be a real feature of the $\mathrm{CD} / 1$ mice.

Other studies of $\mathrm{CD} / 1$ mice at the LM level are consistent with our findings in that fibrocyte degeneration precedes hair cell loss (Wu and Marcus 2003). However, since the $\mathrm{CD} / 1$ mouse is an outbred strain, the genetic background is likely to be quite variable between different populations housed in different institutions, making direct comparison of published data from other CD/1 mouse studies with our own subject to uncertainty. We have not yet established the precise pattern of hearing loss in the mice in our facility, although weakened acoustic startle reflexes are evident by 15 weeks, and cannot therefore ascribe a specific pathological feature to the loss of hearing. Nevertheless, our data and other $\mathrm{CD} / 1$ mice studies are consistent in that presbycusic changes could be initiated by fibrocyte degeneration. We postulate that if this is the case, it is likely to be due to breakdown of homeostatic processes in the cochlea, in which the fibrocytes participate (see review by Wangemann 2006), leading to changes in other cochlear structures (see below).

\section{Patterns of fibrocyte degeneration}

The pattern of fibrocyte loss varies between different strains: in aging C57BL/6 mice types I, II and predominantly IV degenerate by 60 weeks (Hequembourg and Liberman 2001); types II and V are more susceptible in the aging gerbil (Spicer and Schulte 2002); and types I, 

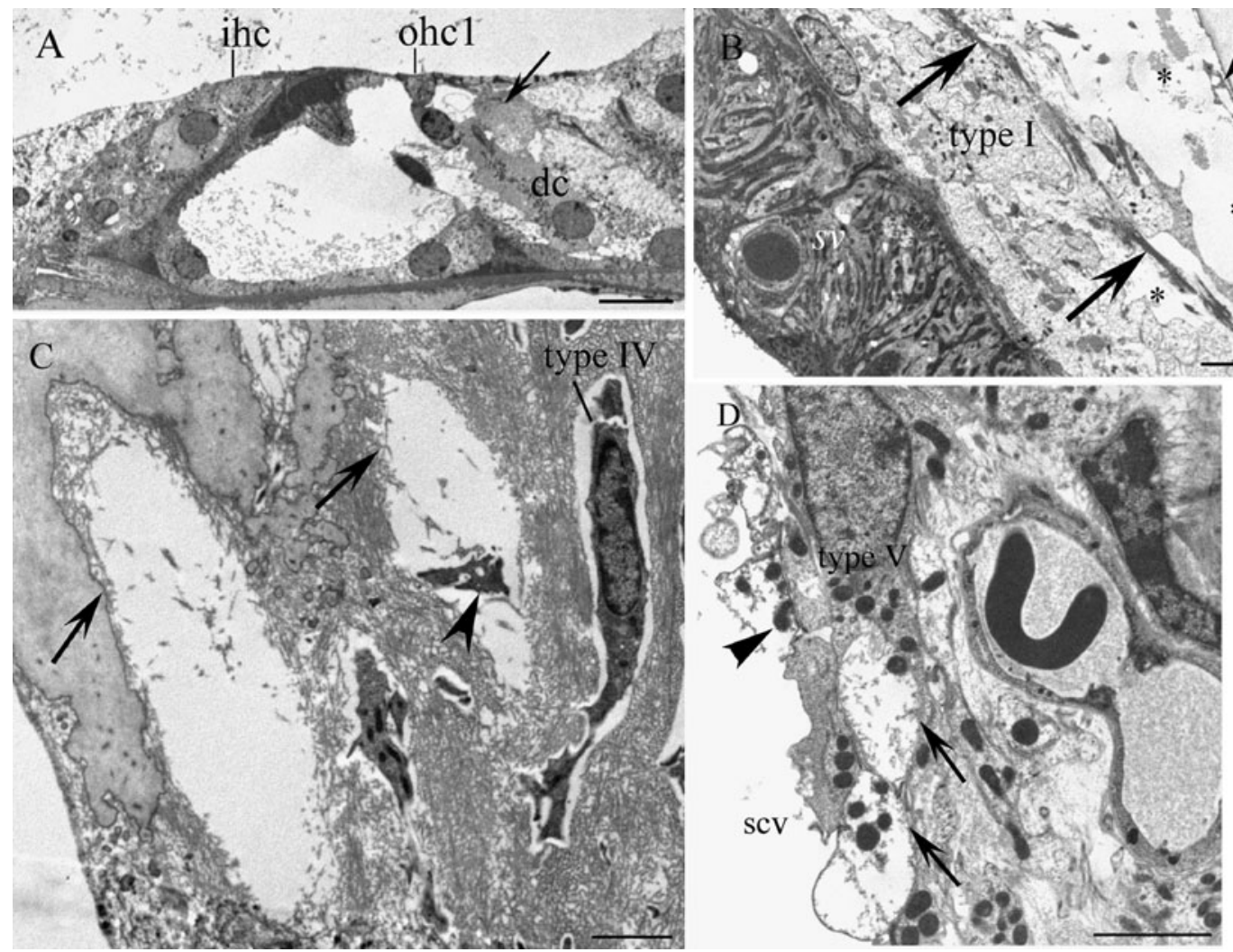

FIG. 10. TEM of radial sections of mice at 15 weeks old. A The organ of Corti has a normal inner hair cell (ihc) and first row outer hair cell (ohc1) but the second and third rows of outer hair cells are missing and a Deiters' cell ( $d c$ ) can be seen expanded (arrow) into the space normally occupied by the latter. B The SV (sv) appeared relatively normal; the upper part of the SL contains empty spaces (asterisk) where type III fibrocytes (small arrows) and type I fibrocytes are missing; some type III (arrowhead) and type I fibrocytes are still present. Extracellular matrix fibres (large arrows) can still be seen adjacent to the empty spaces where the cells are missing. C The basilar crest area of the SL contained large spaces (arrows) with small remnants of cytoplasm and disintegrating nuclei (arrowhead) of the type IV fibrocytes in a late stage of degeneration, as well as a normal type IV fibrocyte. D Supra-strial region of the SL showing a type $\mathrm{V}$ fibrocyte with large vacuoles containing mitochondria (arrows) and degenerating processes (arrowhead) that extend into the scala vestibuli (scv). Bar=10 $\mu \mathrm{m}$ (A and B); bar=2 $\mu \mathrm{m}(\mathbf{C}$ and $\mathbf{D})$.

II, III and IV, predominantly types II and IV, in the aging human cochlea (Kusunoki et al. 2004). In humans, the loss of types II and IV fibrocytes occurs in all turns but is most severe in the apical turn even in infants (Kusunoki et al. 2004). The most consistent feature of these data is that types II and IV cells are the most likely to degenerate, but there are clearly exceptions.

In the $\mathrm{CD} / 1$ mouse, our counts of fibrocytes at 20 weeks old show significant reductions in types II, III and IV compared with 3 weeks, consistent with observations by Wu and Marcus (2003) where basal type IV loss was noted as early as 5 weeks. Type V fibrocytes are the least affected up to 20 weeks. More advanced changes culminate in 72-week-old mice in loss of virtually all fibrocytes in the type IV region and severe reductions in the others. Loss of type IV fibrocytes has also been noted as one of the forms of pathology in Fisher 344 rats (Buckiova et al. 2006), suggesting that it may be a common feature of presbycusis.

To assess whether this pattern of fibrocyte loss is consistent with the extent of early mitochondrial damage, we analysed the proportion of mitochondria showing varying extents of disruption from normal to extreme in the different fibrocyte types. The type $\mathrm{V}$ fibrocytes have fewer damaged mitochondria at least up to 10 weeks, consistent with the fact that they are least likely to go missing. Types III and IV fibrocytes show at the earliest stage the most abnormal mitochondria, consistent with their more rapid degeneration initially. Thus, there is a potential correspondence between mitochondrial damage and the susceptibility of the fibrocytes but further data are needed to confirm this.

\section{Ultrastructural features of fibrocyte degeneration}

As well as early mitochondrial damage, subsequent ultrastructural changes include vacuolization and chromatin alterations that probably indicate an apoptotic process, in line with observations by Mizutari et al. (2008). The latter study implicated mitochondrial dysfunction. Similar cytoplasmic vacuolization and mitochondrial degeneration were also evident in 

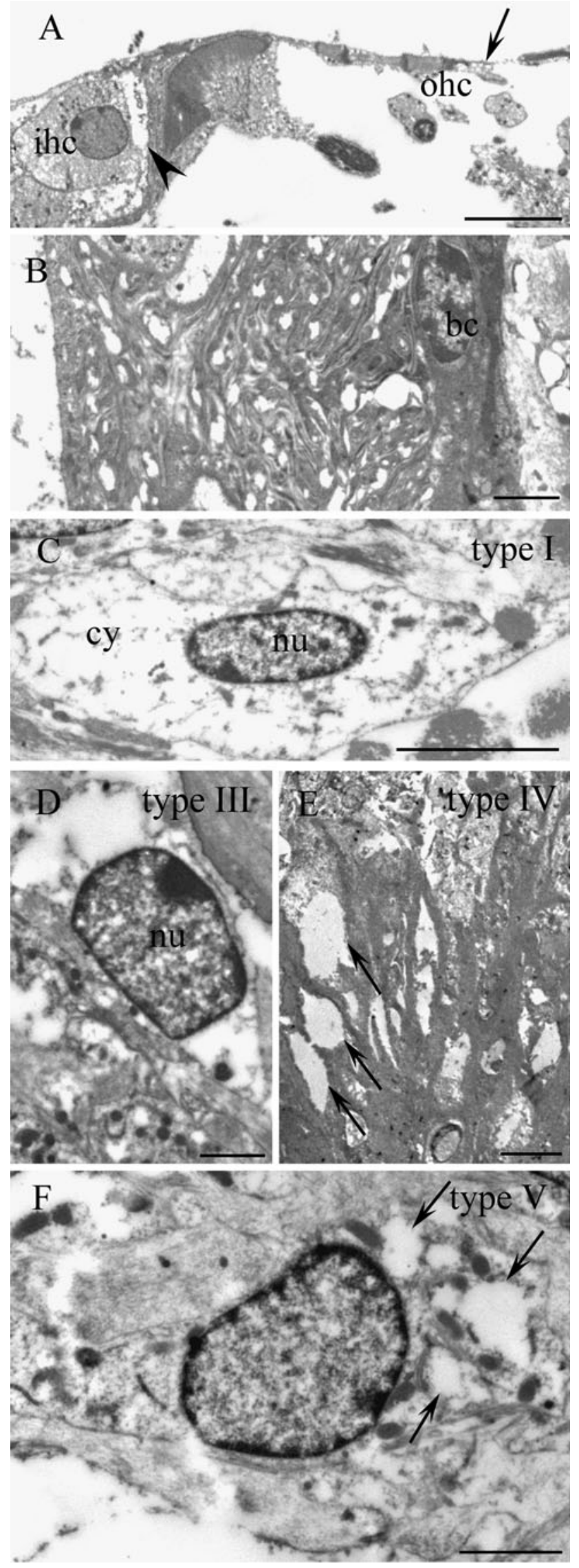

FIG. 11. TEM of 20-week-old mice. A Radial section of an organ of Corti with damaged outer hair cell region (ohc) and loss of the third row of outer hair cells (arrow). The supporting cell (arrowhead) surrounding the inner hair cell (ihc) also appears damaged. B Some regions of the SV show degeneration; the region illustrated here shows white vacuoles associated with swollen mitochondria. C The cytoplasm (cy) of the type I cell has very few organelles; nucleus ( $n u)$. D The cytoplasm of type III fibrocyte is substantially reduced leaving a large space surrounding the cell; nu. E Large gaps (arrows) in the extracellular matrix are due to loss of some of the type IV fibrocytes in the basilar crest region of the SL. F The cytoplasm of type $\mathrm{V}$ fibrocytes appear shrunken, shows significant disruption (arrows) and contains a few mitochondria. Bar=10 $\mu \mathrm{m}(\mathbf{A}$ and $\mathbf{E})$; bar $=5 \mu \mathrm{m}(\mathbf{C})$; bar $=2 \mu \mathrm{m}(\mathbf{B}, \mathbf{D}$ and $\mathbf{F})$.

some of the fibrocytes types in 33-36 months old gerbil cochlea (Spicer and Schulte 2002) suggesting that age-relate changes in the $\mathrm{CD} / 1$ mouse, although accelerated, have similar features to longer term aging in gerbils.

The most prominent degeneration we observed was in the basilar crest area of the SL where type IV fibrocytes appear to disintegrate resulting in large spaces containing remnants of cytoplasm/nucleus, and by 15 weeks gaps can be seen due to loss of the cells. Clear spaces with narrowed processes of type II fibrocytes have been observed in the 10-week-old CD/1 mice, similar to the aging gerbil cochlea (Spicer and Schulte 2002). Gaps are also seen in the type I area due to loss of type I fibrocytes in the 15-week-old $\mathrm{CD} / 1$ mice and the type III area after 20 weeks.

\section{The causes of fibrocyte degeneration}

Fibrocyte degeneration is not a general phenomenon in mice; moreover, genetic factors play a role in accelerated age-related changes in many mice: a gene for age-related hearing loss $(a h l)$ has been found in C57BL/6J and in nine other inbred mouse strains (Johnson et al. 2000) but not in the CBA/CaJ strain which has minimal hearing loss and normal organ of Corti at 34 weeks and 25 months old (Hequembourg and Liberman 2001; Wu and Marcus 2003). A genetic basis for presbycusis has not been investigated in $\mathrm{CD} / 1$ mice.

In another model of aging, it has been reported that hair cell loss is exacerbated by copper/zinc superoxide dismutase deficiency (McFadden et al. 1999). This implies involvement of the superoxide radical, failure to eradicate which may lead to mitochondrial damage. The morphological changes we observe in mitochondria in fibrocytes and SV which show quite extreme levels of damage could be representative of a similar deficiency. The appearance of vacuoles within the mitochondria implies breakdown of the ion and water balances within them. With greater damage, the enzymatic activity of the mitochondria 

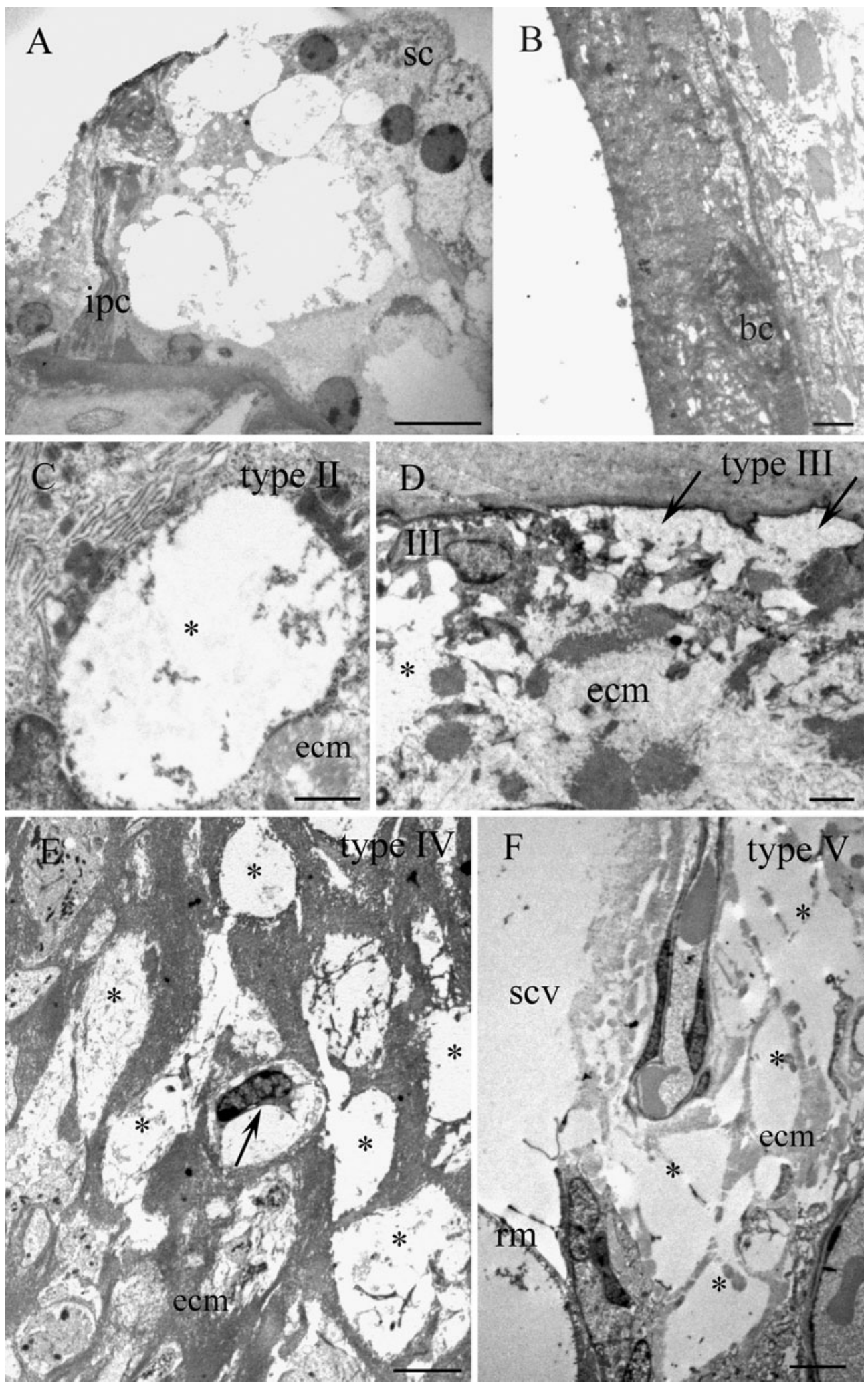

FIG. 12. TEM of 52-week-old mice. A Radial section of a degenerated organ of Corti with loss of inner and outer hair cells, and the supporting cells $(s c)$ occupying the region of degenerated outer hair cells; inner pillar cell (ipc). B SV in the basal turn is thinner than in younger animals with possible cell depletion. However, the normal three layers of cells can usually be distinguished, including basal cells (bc). C Loss of a type II cell (asterisk), the extracellular matrix around the gap is still present. D Region of the SL lateral to the SV with loss of type I (asterisk) and type III (arrows) cells but with remaining extracellular matrix $(\mathrm{ecm})$. E Basilar crest region with a remaining type IV cell (arrow), and the majority of the type IV cells degenerated (asterisk). F Supra-SV region with degenerated type V cells (asterisk) but with remaining ecm. rm Reissner's membrane, SCV scala vestibuli. Bar=10 $\mu \mathrm{m}(\mathbf{A}), 1 \mu \mathrm{m}(\mathbf{C}), 2 \mu \mathrm{m}(\mathbf{B}$ and $\mathbf{D}), 5 \mu \mathrm{m}(\mathbf{E}$ and $\mathbf{F})$. 


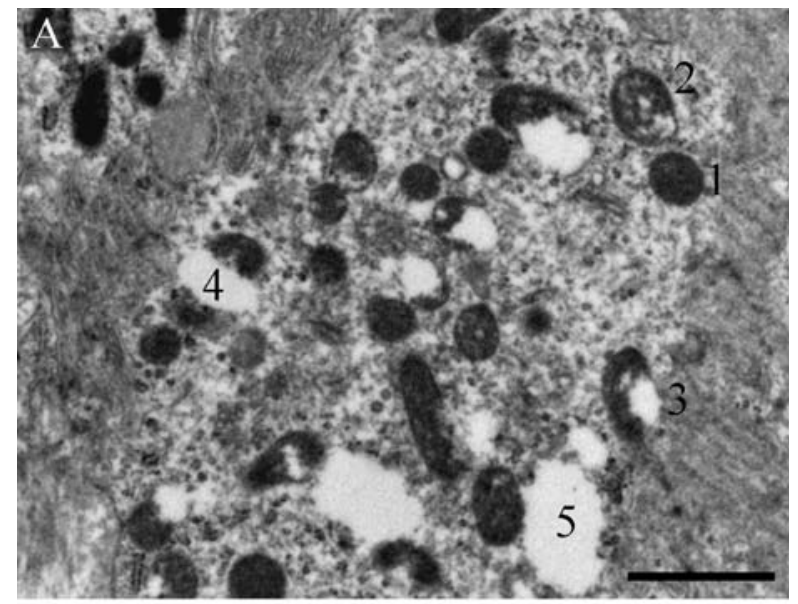

B

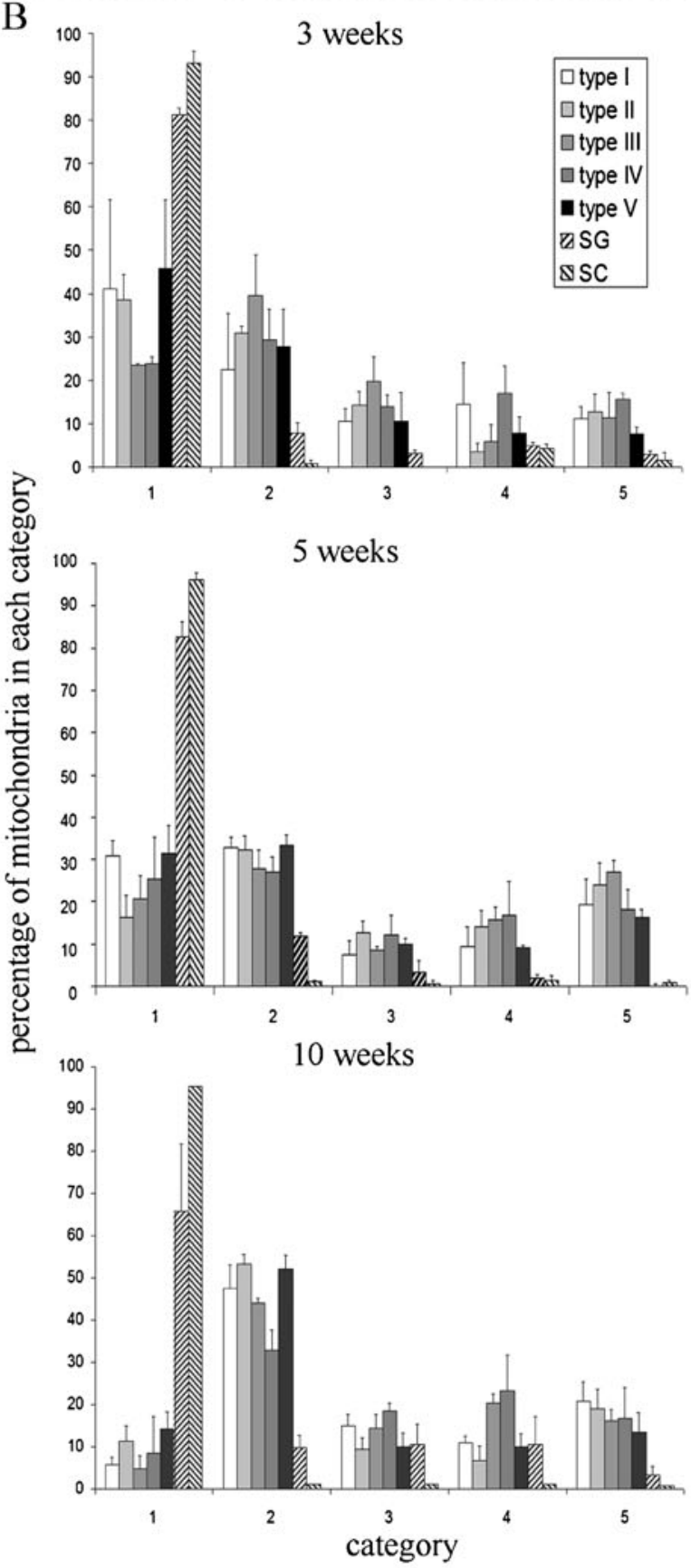

FIG. 13. A TEM of a region of fibrocyte cytoplasm showing the categorisation of damage levels used for quantitative assessment of mitochondria, indicated by numbers 1 (undamaged) to 5 (gross damage). Bar=1 $\mu \mathrm{m}$. B Histograms showing how the levels of damage in SL and SG change between 3-, 5- and 10-week-old animals. Note that the proportion of category 1 (undamaged) mitochondria decreases whilst the proportion of category 2, in particular, increases with age in the fibrocytes (Tye I-V). Mitochondrial damage was limited in satellite cells (SC) and in SG neurons, increasing slightly at 10 weeks in the latter.

seems to be reduced. Thus, we postulate that the mitochondrial damage is a contributory factor to fibrocyte degeneration and subsequently to the hair cell loss. Mutations in mitochondrial genes are a common cause of human deafness (Fischel-Ghodsian 1999), and it is possible that the $\mathrm{CD} / 1$ mouse also suffers an mtDNA mutation that generates the accelerated age-related pathology. Mutations in mtDNA are also common in general in aging and can accumulate over time until they reach a critical level (Seo et al. 2010).

The lack of mitochondrial damage in hair cells, and the weak level detected in SG neurons suggests that there is a tissue-specific difference as well as genetic susceptibility; it may be that higher energy demands in the SL result in greater damage to susceptible mitochondria through the generation of greater amounts of free radicals (Seo et al. 2010). In addition, cells can show heteroplasmy where mutated

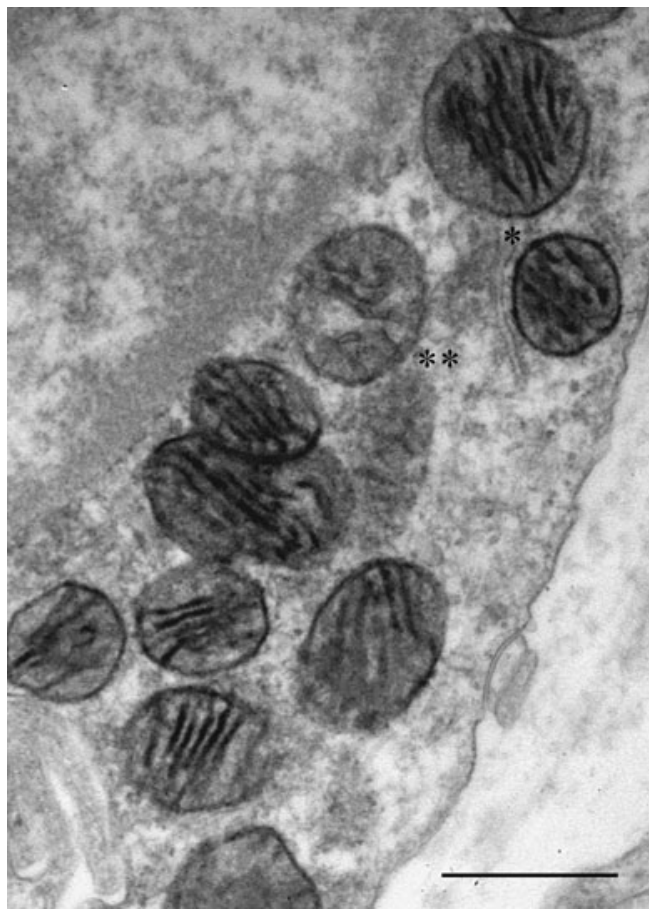

FIG. 14. Examples of the cytochrome oxidase-DAB reaction in mitochondria. More damaged mitochondria (double asterisks) frequently show a lower level of reaction product than normal ones (asterisk). Bar=500 nm. 
and wild type mtDNA coexist. Thus variable degrees of tissue-specific effect are not surprising.

\section{Mechanisms of presbycusis caused by fibrocyte degeneration}

In this study, mitochondrial degeneration is clearly present early on in the presbycusic process and may produce functional loss before actual loss of the fibrocytes. It could explain reports that hearing impairment is present in some $\mathrm{CD} / 1$ mice younger than 5 weeks (Shone et al. 1991; Le Calvez et al. 1998a, b) when in our mice there is no major loss of cells at this age and it may contribute by causing specific lateral wall pathophysiology such as loss of the EP. How this early mitochondrial damage relates to the subsequent progressive hearing loss is not known. It is not certain that it leads to the degeneration of the fibrocytes, and potential breakdown of homeostatic mechanisms due to fibrocyte loss, but it may be one factor.

As with other presbycusic models, there is also increasing SV, SG and hair cell damage with time, here lagging behind fibrocyte damage. The SV varies considerably in its degenerative state, with some normal structure even at 52 weeks, but also shows mitochondrial damage. Outer hair cells became substantially damaged or lost between 15 and 20 weeks in the basal turn; inner hair cells and their supporting cells also begin to degenerate by this age. This is consistent with other studies showing that degeneration of the organ of Corti in the aging $\mathrm{CD} / 1$ mice progresses from base to apex; in 28-week-old CD/1 mice the organ of Corti in basal turn is replaced by simple epithelial cells ( $\mathrm{Wu}$ and Marcus 2003). It seems likely that the increasingly substantial hearing loss seen later in most $\mathrm{CD} / 1$ mice mostly reflects the hair cell loss.

The lack of mitochondrial pathology and the later onset of damage to hair cells and SG are consistent with our hypothesis that fibrocyte degeneration could initiate the pathology of the organ of Corti and auditory nerve. A possible process leading to hair cell degeneration is breakdown of $\mathrm{K}^{+}$recycling from the perilymph surrounding the hair cell bases due to degeneration of the SL and subsequently SV. Excessive $\mathrm{K}^{+}$in hair cells appears to result in hair cell death (Nouvian et al. 2003). This toxicity is probably avoided only if $\mathrm{K}^{+}$is continuously pumped out of the perilymph, a process dependent on fibrocytes (see review by Wangemann 2006).

\section{CONCLUSIONS}

We have observed that subtle changes, primarily in mitochondria, occur quite soon after birth in all fibrocytes in $\mathrm{CD} / 1$ mice, and these degenerative changes progress to loss particularly of types II, III and IV fibrocytes. The early changes, we suggest, are a prelude to SV, SG and hair cell damage. Later features of the aging process, although accelerated, are similar to other rodent models and to humans. This means the $\mathrm{CD} / 1$ mouse could be a model for presbycusis caused potentially by fibrocyte loss, although functional studies are required to confirm this mechanism. Early intervention to prevent or repair fibrocyte damage, e.g. with stem cells, is a possible way forward to prevent the presbycusic changes.

\section{ACKNOWLEDGEMENTS}

Work supported by Deafness Research UK, the Grand Charity and the Henry Smith Charity. We are indebted to Karen Walker for technical help and to Dr. DM Lawton for supplying micrograph F for Fig. 1.

\section{REFERENCES}

Buckiova D, Popelar J, Syka J (2006) Collagen changes in the cochlea of aged Fischer 344 rats. Exp Gerontol 41:296-302

Delprat B, Ruel J, Guitton MJ, Hamard G, Lenoir M, Pujol R, Puel JL, Brabet P, Hamel CP (2005) Deafness and cochlear fibrocyte alterations in mice deficient for the inner ear protein otospiralin. Mol Cell Biol 25:847-853

Donadieu E, Hamdi W, Deveze A, Lucciano M, Lavieille JP, Magnan J, RIVA C (2007) Improved cryosections and specific immunohistochemical methods for detecting hypoxia in mouse and rat cochleae. Acta Histochem 109:177-184

Fischel-GHodsian N (1999) Mitochondrial deafness mutations reviewed. Hum Mutat 13:261-270

Furness DN, Lawton DM, Mahendrasingam S, Hodierne L, Jagger DJ (2009) Quantitative analysis of the expression of the glutamateaspartate transporter and identification of functional glutamate uptake reveal a role for cochlear fibrocytes in glutamate homeostasis. Neurosci 162:1307-1321

Hequembourg S, Liberman MC (2001) Spiral ligament pathology: a major aspect of age-related cochlear degeneration in C57BL/ 6 mice. JARO 2:118-129

Hildebrand MS, Tack D, McMordie SJ, Deluca A, Hur IA, Nishimura C, Huygen P, Casavant TL, Smith RJ (2008) Audioprofile-directed screening identifies novel mutations in KCNQ4 causing hearing loss at the DFNA2 locus. Genet Med 10:797-804

Hirose K, Liberman MC (2003) Lateral wall histopathology and endocochlear potential in the noise-damaged mouse cochlea. JARO 4:339-352

Ichimiya I, Kuruno Y, Hirano T, Mogi G (1998) Changes in immunostaining of inner ears after antigen challenge into the scala tympani. Laryngoscope 108:585-591

Ichimiya I, Suzuki M, Hirano T, Mogi G (1999) The influence of pneumococcal otitis media on the cochlear lateral wall. Hear Res 131:128-134

Ichimiya I, Yoshida K, Hirano T, Suzuki M, Mogi G (2000) Significance of spiral ligament fibrocytes with cochlear inflammation. Int J Paediatr Otolaryngol 56:45-51

JoHnSON KR, ZHENG QY, ERWAY LC (2000) A major gene affecting agerelated hearing loss is common to at least ten inbred strains of mice. Genomics 70:171-180 
Kusunoki T, Cureoglu S, Schachern PA, Baba K, Kariya S, Paparella MM (2004) Age-related pathologic changes in the human cochlea: a temporal bone study. Otolaryngol Head Neck Surg 131:897-903

Le Calvez S, Avan P, Gilain L, Romand R (1998A) CD1 hearing impaired mice. I: distortion product otoacoustic emission levels, cochlear function and morphology. Hear Res 120:37-50

Le Calvez S, Guilhaume A, Romand R, Aran JM, Avan P (1998в) CD/1 hearing impaired mice. II: group latencies and optimal $\mathrm{f}_{2} / \mathrm{f}_{1}$ ratios of distortion-product otoacoustic emissions, and scanning electron microscopy. Hear Res 120:51-61

McFadden SL, Ding D, Reaume AG, Flood DG, Salvi RJ (1999) Agerelated cochlear hair cell loss is enhanced in mice lacking copper/zinc superoxide dismutase. Neurobiol Aging 20:1-8

Minowa O, Ikeda K, Sugitani Y, Oshima T, Nakai S, Katori Y, Suzuki M, Furukawa M, Kawase T, Zheng Y, Ogura M, Asada Y, Watanabe K, Yamanaka H, Gotoh S, Nishi-Takeshima M, Sugimoto T, Kikuchi T, TAKASAKa T, NoDA (1999) Altered cochlear fibrocytes in a mouse model of DFN3 nonsyndromic deafness. Science 285:1408-1411

Mizutari K, Matsunaga T, Kamiya K, Fuginami Y, Fugi M, Ogawa K (2008) Caspase inhibitor facilitates recovery of hearing by protecting the cochlear lateral wall from acute cochlear mitochondrial dysfunction. J Neurosci Res 86:215-222

Nakazawa K, Spicer SS, Schulte BA (1995) Ultrastructural localization of $\mathrm{Na}$, K-ATPase in the gerbil cochlea. J Histochem Cytochem 43:981-991

Nouvian R, Ruel J, Wang J, Guitton MJ, Pujol R, Puel JL (2003) Degeneration of sensory outer hair cells following pharmacological blockade of cochlear KCNQ channels in the adult guinea pig. Eur J Neurosci 17:2553-2562

Okamoto Y, Hoya N, Kamiya K, Fuji M, Ogana K, Matsunaga T (2005) Permanent threshold shift caused by acute cochlear mitochondrial dysfunction is primarily mediated by degeneration of the lateral wall of the cochlea. Audiol Neurootol 10:220-233

Perotti ME, Anderson WA, Swift H (1983) Quantitative cytochemistry of the diaminobenzidine cytochrome oxidase reaction product in mitochondria of cardiac muscle and pancreas. J Histochem Cytochem 31:351-365
Riva C, Longuet M, Lucciano M, Magnan J, Lavieille JP (2005) Implication of mitochondrial apoptosis in neural degeneration in a murin model for presbycusis. Rev Laryngol Otol Rhinol 126:67-74

Riva C, Donadieu E, Magnan J, Lavieille JP (2007) Age-related hearing loss in $\mathrm{CD} / 1$ mice is associated to ROS formation and HIF target proteins up-regulation in the cochlea. Exp Gerontol 42:327-336

Schuknecht HF, Gacek MR (1993) Cochlear pathology in presbycusis. Ann Otol Rhinol Laryngol 102:1-16

Seligman AM, Karnovsky MJ, Wasserkrug HL, Hanker JS (1968) Nondroplet ultrastructural demonstration of cytochrome oxidase activity with a polymerising osmiophilic reagent, diaminobenzidine (DAB). J Cell Biol 38:1-14

Seligman AM, Shannon WA Jr, Hoshino Y, Plapinger RE (1973) Some important principles in 3,3'-diaminobenzidine ultrastructural cytochemistry. J Histochem Cytochem 21:756-758

Seo AY, Joseph AM, Dutta D, Hwang JCY, Aris JP, Leeunenburgh C (2010) New insights into the role of mitochondria in aging: mitochondrial dynamics and more. J Cell Sci 123:2533-2542

Shone G, Raphael Y, Miller JM (1991) Hereditary deafness occurring in CD/1 mice. Hear Res 57:153-156

SPICER SS, SCHulte BA (1991) Differentiation of inner ear fibrocytes according to their ion transport related activity. Hear Res 56:5364

SPICER SS, Schulte BA (2002) Spiral ligament pathology in quietaged gerbils. Hear Res 172:172-185

Suko T, Iснimiya I, Yoshida K, Suzuki M, Mogi G (2000) Classification and culture of spiral ligament fibrocytes from mice. Hear Res 140:137-144

WANGEMANN P (2006) Supporting sensory transduction: cochlear fluid homeostasis and the endocochlear potential. J Physiol 576:11-21

Weber PC, Cunningham CD, Schulte BA (2001) Potassium recycling pathways in the human cochlea. Laryngoscope 111:1156-1165

Wu T, Marcus DC (2003) Age-related changes in cochlear endolymphatic potassium and potential in $\mathrm{CD} / 1$ and $\mathrm{CBA} / \mathrm{CaJ}$ mice. JARO 4:353-362 